Environmental Research Journal 6(5): 329-332, 2012

ISSN: 1994-5396

(C) Medwell Journals, 2012

\title{
Wastewater Management from Toilets on Air-Conditioned Buses in Thailand
}

\author{
${ }^{1}$ Yongyod Rapeepan and ${ }^{2}$ Charerntanyarak Lertchai \\ ${ }^{1}$ Public Health Program, Graduate School, \\ ${ }^{2}$ Faculty of Public Health, Khon Kaen University, 40002 Khon Kaen, Thailand
}

\begin{abstract}
The purpose of this survey research was to study wastewater management from toilets on airconditioned buses traveling from Khon Kaen province to Bangkok. Data was collected using purposive sampling from the three most popular companies which make many trips daily. Statistical data from the Department of Land Transport showed that the average number of passengers traveling by air-conditioned buses were 27,910 per day. Samples in this study consisted of 70 drivers and bus boys and 252 passengers from three major Thai bus companies; the survey was conducted using questionnaires and observation. The results showed that $>90 \%$ of buses drained wastewater on the side of the road or released it into drainage pipes or waterways before reaching the bus terminal. Wastewater from toilets on air-conditioned buses contained urine and stools that were untreated with disinfectants. When this wastewater is released into the environment, it can cause the spread of contagious diseases. It is essential that wastewater must be treated and transferred to a treatment plant in order to protect the natural environment and the health of the population. Wastewater from toilets on air-conditioned buses should be discharged at a proper wastewater plant where it will go through the appropriate treatment process before being released into the environment.
\end{abstract}

Key words: Waste water disposal, waste water management, plant, treatment, Bangkok, Thailand

\section{INTRODUCTION}

At present, Thailand's emphasis in terms of sanitation and people's quality of life is to provide physical, mental and social well-being together with dignity in all aspects of life. Basic well-being includes a hygienic house, clean water for consumption and a good quality of life. However, nationwide efforts toward achieving a better level of sanitation in public toilets have been uneven at best. A recent study (Ayutthaya and Rakros, 2007) assessed the quality of public toilets and user behavior in Thailand. The findings showed that only 507 out of 1,237 public toilets achieved a rating of Health Accessibility Safety as determined by the 4th Regional Health Promotion Centre.

Many countries around the world, particularly in underdeveloped areas are becoming increasingly aware of the importance of public sanitation. Toilets must be clean, safe and accessible. Another important factor is that wastewater must be handled correctly in order to minimize illness and death stemming frominfectious gastrointestinal diseases (WHO, 2002).

Outbreaks of such diseases originate from several factors. One of the most common causes is inappropriate hygiene habits. For example, people may sometimes not use a toilet when they defecate, perhaps due to the unavailability of toilets.
In Thailand, one major potential health problem concerns air-conditioned buses equipped with toilets which often empty their wastewater holding tanks at the side of the road instead of waiting until they reach the terminal. Such behavior could contaminate water and food resources with wastewater and cause the spread of diseases.

Public transportation by bus is an important factor for economic and social growth in Thailand because it is a basic public utility required by a large number of consumers each day. It was found that in 2007,625.5 million people used the transport systems of the Bangkok Mass Transit Authority (BMTA) and the Transport Co. Ltd. Thailand's Land Transport Act in 1979 does not address the issue of wastewater on airconditioned buses, only the characteristics of buses. Only the Public Health Act in 1992 directly discusses the disposal of waste:

Forbidding the discharging, emptying, leaving or causing to exist in a public place or way of sewage or solid waste except in the place provided by the local government for such purpose

although, there is no specific mention of the disposal of wastewater on air-conditioned buses (Sithichoksakulchai, 1990).

Corresponding Author: Yongyod Rapeepan, Public Health Program, Graduate School, Khon Kaen University, 40002 Khon Kaen, Thailand 
Many officials in the related government sectors either are unaware of the situation or refuse to acknowledge this critical problem which affects many aspects of the country's health and well-being. Moreover, there are no nationwide regulations or standards regarding toilets on air-conditioned buses.

\section{MATERIALS AND METHODS}

This survey was conducted by interviewing employees and passengers of three air-conditioned bus companies traveling on the Khon Kaen to Bangkok route. These companies all make multiple trips per day and are more popular than other bus companies in the region. Purposive sampling was used. Subjects consisted of 70 drivers and bus boys and 252 passengers. This study received an ethics waiver from the Khon Kaen University Ethics Committee (reference number HE 542003).

\section{RESULTS AND DISCUSSION}

This survey research aimed to study wastewater management in toilets on air-conditioned buses. Wastewater is one of the most serious environmental problems in Thailand and includes industrial, agricultural and domestic wastewater. One source of water pollution in Thailand is wastewater or wastewater discharged from toilets on air-conditioned buses. Thousands of passengers ride on these air-conditioned buses every day. And the presence of toilets on these buses is considered to be a necessity by passengers because of the very long distances of many trips with few rest stops along the way.

Wastewater from air-conditioned bus toilets consists of passengers' urine and stool. At present, bus companies generally do not properly treat this waste before releasing it into the environment. The release of wastewater from air-conditioned bus toilets is associated with bus companies' attempts to maintain quality standards in terms of cleanliness and odor. Especially during long holiday periods when buses transport many more passengers than usual, the amount of wastewater is dramatically increased and holding tanks fill up rapidly. It is more difficult to control the resulting odors and therefore the wastewater is released into the environment sometime during the trip. Another cause of wastewater contamination of the environment is leakage from old holding tanks on some buses.

At present, no official standards for toilets on airconditioned buses in Thailand have been determined; also, no regular inspection and maintenance of toilets is conducted. One of the main problems resulting from the lack of official guidelines is the unregulated release of wastewater into the environment. If improperly treated, this could result in the rapid spread of diseases, particularly during the rainy season, affecting the health of local residents.

The survey found that $76.2,88.9$ and $80 \%$ of samples from companies $\mathrm{A}, \mathrm{B}$ and $\mathrm{C}$, respectively had not been treated with disinfectant before discharging the wastewater into the environment. Consequently, there was the potential that diseases in the wastewater could be dispersed into the environment. Most of the officials from all three bus companies expressed the opinion that the most significant problem was bad odors emanating from the toilet $(97.6,61.1$ and $85 \%$, respectively) and consequently deodorizers were used in an attempt to solve the problem. The toilets were also considered to be not clean $(61.9,77.8$ and $75 \%$, respectively). In addition, toilets and holding tanks were often old, increasing their susceptibility to damage and leaks. The capacity of waste holding tanks was considered to be adequate during the low season however during the high season or busy holiday periods, holding capacity became a problem because of the increased number of passengers, often resulting in mid-trip disposal of wastewater.

\section{Management of wastewater from bus toilets}

Disposal on the side of the road: It was found that all three companies had occasionally or frequently disposed of wastewater on the roadside after passengers had exited the bus at the terminal. No type of disinfectant was used before draining the wastewater into the environment, leading to the risk of disease transmission.

Disposal into municipal drainage: Some companies discharged wastewater into municipal drainpipes. From interviews with bus officials, it was determined that the reason for disposing the waste into the municipal drainpipe was because the waste tanks were full. Unfortunately, the drainpipe system in Thailand does not separate wastewater pipes from rainwater pipes and therefore this could be a means of rapid transmission of diseases to the public.

Disposal at company location: Sometimes Company C emptied the wastewater into the company's septic tank. None of them added antiseptics before disposal. The waste from air-conditioned bus toilets mostly consists of stools and urine; therefore, a disinfectant must first be added before releasing the wastewater in order to avoid harmful effects on humans and the environment. All effluent from septic tanks should be discharged into a well-designed and maintained soil absorption field or a properly designed sewage treatment plant. 
None of the bus drivers were aware of the disposal area provided at the main Northern Bangkok bus terminal (Mo Chit station). Even so, nearly all of them admitted that they would not be likely to dispose of the waste at that area because it was inconvenient and timeconsuming.

Interviews with the drivers and bus boys of Company A regarding the discharge of wastewater from bus toilets produced the following responses:

- Dispose of it in the company's drained and then flushes it with water

- There is a drain that the company provides at the rest area

- If it is not a crowded area, I will have the bus pull over and empty the toilet on the roadside

- Dispose of the wastewater somewhere that is not crowded or whenever the bus stops at a rest area

- Dispose of the wastewater into the drain at the gas station

- Dispose of the wastewater every time the bus stops at a gas station for fuel

The information from this interview showed that the drivers and bus boys were not aware of the environmental issues. That is they were unconcerned about disposing of wastewater in public drains or waterways or in rice fields in the countryside. This could constitute a serious nationwide problem if as is unfortunately likely bus drivers and bus boys in every province used the same waste disposal methods as they do on the Khon Kaen Bangkok route. Concerned authorities should urgently address this issue to find solutions and establish preventive measures.

When asked about their methods of disposal of wastewater, the drivers and bus boys of Company B said that wastewater was disposed of on the roadside, at each company's garage or in sparsely populated locations. The bus drivers and attendants' statements were as follows:

- Dispose of it when getting to the destination

- Dispose of it when getting to the garage

- Empty the holding tank when it's full and pull over at the proper place to dispose of it

- Dispose of it at the place designated by the Department of Land Transport or at the proper time and occasion

- Dispose of it at the garage

Based on the interviews with these drivers and bus boys, it appears that the waste disposal often was not done properly. The waste consisted of urine and feces which is likely to adversely affect the environment if disposed of improperly. Some of them were unaware of the consequences of improper disposal such as the environmental effects or whether the company provided a facility for disposal.

In interviews with the bus drivers and bus boys of Company $\mathrm{C}$, it was found that they disposed of wastewater either by draining it into the company's septic tank or by disposing of it somewhere in an unpopulated area. The statements obtained were as follows:

- When arriving at the destination, dispose of it

- Dispose of it when arriving at the garage

- Dispose of it at the last rest area

- Dispose of it at the destination's garage

- If the holding tank is full during the trip, dispose of it somewhere properly

The above answers indicated that the bus drivers and bus boys were not aware of the danger and impact of releasing untreated wastewater into the environment. One possible solution is that there should be an authorized agent at each company to control the process of disposal.

Analysis and finding: Survey results revealed how the wastewater from air-conditioned buses was managed by each of the three bus companies. Company A offers two types of services, consisting of first-class and VIP buses. Each type of bus has differences in facilities and cleanliness as well in the design of the wastewater tanks. The first-class buses have flush toilets while the VIP buses have cesspool toilets that need to be rinsed with water after use. Company A used three methods for disposing of wastewater, i.e., on the roadside, at the bus terminal and at gas stations where there was access to a septic tank.

Like Company A, Company B has two types of buses and similar methods of wastewater management. However, Company B also discharged wastewater into municipal drains. Unfortunately, municipal pipes do not separate wastewater and rain water so, when wastewater from toilets enters the drains, it can cause the rapid spread of disease.

Company $\mathrm{C}$ discharged wastewater at bus terminals, along the roadside and into municipal drains. The data collected from the drivers and bus boys of the three bus companies showed that $>90 \%$ of the buses have discharged wastewater on the side of the road. Some companies have also dumped wastewater into sewage drains without proper treatment, i.e., no disinfectant was applied before disposal. 
Housekeepers cleaned the toilets before every trip. Nevertheless, most of the surveyed passengers mentioned that the toilets smelled bad and were not very attractive; they believed that this was most likely due to inadequate (not thorough) cleaning on a regular basis and also because the toilets were not cleaned during the trip. The bad odor was especially noticeable to those sitting in seats adjacent to the toilet. Passengers said that at the beginning of the trip, there was normally no bad smell. However, as time passed by, the bad smell became very strong. This problem was discussed with the housekeepers who admitted that they did not know how to handle it. No matter how diligently they cleaned, the bad smell remained. Naturally, this is a major annoyance to passengers.

This might be caused by improper ventilation. Since, buses are often designed with a small-sized toilet in order to allow the maximum number of passenger seats, this could result in inadequate ventilation. Some toilets did not have any ventilation system at all. From observation, it was found that the toilet window was often tinted black to prevent sunlight from entering. This could be another reason for the persistent bad smell. Several passengers mentioned that they did not want to use the toilet on an air-conditioned bus because they felt it was not clean or safe.

From an analysis of the bad odor and cleanliness problem, it appears that bus company managers did attempt to maintain certain standards of cleanliness but these were difficult to control because of the timing of trips (fast turnaround time) or in instances when there were an unusually high number of passengers. Each individual passenger also had different habits and standards of hygiene. Hence, the cleanliness level of the toilet of each air-conditioned bus was different.

\section{CONCLUSION}

Improper disposal of wastewater from air-conditioned buses can harm the environment including the soil, water and air. It also has the potential to affect the health of people living in nearby areas as it can be a source of disease. However, as yet there is no government agency officially assigned to regulate this issue. The following problems were found:
- Bus drivers and bus boys had inadequate knowledge concerning wastewater management and were unaware of the adverse impacts of improper disposalof wastewater into the environment. Bus drivers from all three companies were unsure about the best methods of where and how to dispose of wastewater

- There is no direct law enforcement regarding the disposal of wastewater from air-conditioned buses. The only existing legislation deals with general waste management. Air-conditioned buses that discharge wastewater into the environment without proper treatment could cause contamination of the soil, water and air and contribute to the potential spread of diseases

- There are no on-board wastewater treatment systems for toilets on air-conditioned buses. Also, at the present time there are only two locations that provide treatment of wastewater from air-conditioned buses. Moreover, most bus drivers have indicated that it is inconvenient to drive out of their way to dispose of wastewater at these designated areas

\section{ACKNOWLEDGEMENT}

This research was supported by the Graduate School, Khon Kaen University, Thailand.

\section{REFERENCES}

Ayutthaya, P.S. and S. Rakros, 2007. The sanitation situation of public health and consumer behaviors. Regional Health Promotion Centre, Ratchaburi, Thailand.

Sithichoksakulchai, S., 1990. The efficiency of disinfectants on coliform bacteria in feces from the toilet of air-conditioned bus. M.S. Thesis, Mahidol University, Bangkok, Thailand.

WHO, 2002. Scaling Up the Response to Infectious Diseases: A Way Out of Poverty. World Health Organization, Geneva, Switzerland, Pages: 126. 